\title{
Influence of Personal Teacher Efficacy on Selection of Teaching Methods in Secondary Schools in Kwale County, Kenya
}

\author{
Ogembo John Otieno \\ Dept. Educational Comm. Tech. \\ South Eastern Kenya University \\ jogemboh@yahoo.com \\ Nduati Sammy Charagu \\ $\mathrm{PhD}$ Student \\ Kenyatta University \\ sncharagu@yahoo.com
}

\author{
Kamau Mwathi Leonard (PhD) \\ Dept. Educational Comm. Tech. \\ South Eastern Kenya University \\ lmkamau@seku.ac.ke
}

Monyoro Wilfred Mogire

\author{
PhD Student \\ Kenyatta University \\ wmogire@yahoo.com
}

\begin{abstract}
Teachers' effective management of the learning situation has and continues to draw the concern of many researchers. This is more so in response to declining standards in learner achievement within the country, Kenya and the need to keep pace with the rest of the world. Since teachers are the primary agents in implementing the curriculum, their personal perceptions concerning the prevailing conditions as well as their ability to contribute in turning around the circumstances through use of innovative techniques ultimately influence instructional strategies they adopt. Personal Teacher Efficacy is an indicator of their willingness or otherwise to embrace a given circumstance. Though data on PTE seems to exist, much of this work has its origin outside Africa. None exist that provides an insight on secondary education management of classroom pedagogy in Kenya. Additionally, most of the existing data show minimal direct link between PTE and teachers' choice of teaching method. Further, their analysis indicates inconsistencies regarding the sources of efficacy information. This study therefore sought to assess the influence of PTE on choice of teaching methods among secondary school teachers in Kwale County as a contribution in furthering this line of research. Data was obtained from 121 (76 male, 45 female) practicing teachers in public secondary schools within the county using a questionnaire comprising of items adapted from the Teachers' Sense of Self-Efficacy Scale (Tschannen-Moran \& Hoy, 2001) and the Mentor Support Scale (Capa \& Loadman, 2004). Results showed that teacher's demographic characteristics of age, gender and teaching experience as well as their mastery of teaching techniques are the main sources of teachers' PTE. Similarly, teachers' age, teaching experience and mastery were found to be significant predictors of their choice of innovative instructional techniques.
\end{abstract}

Keywords: Teacher efficacy, Vicarious experiences, Mastery

\section{INTRODUCTION}

Teachers' effective management of the learning situation has and continues to draw the concern of many researchers. Lately, with studies focusing more and more on adoption of methods that incorporate modern technology as instructional tools, focus has shifted to the ability of the teacher to effectively manage the enriched classroom environment (Ogermbo, Ayot \& Twoli, 2015; Miima, Ondigi \& Mavisi, 2013). Personal Teacher Efficacy (PTE) has therefore become the centre of focus of many studies (Klassen, Tze, Betts \& Gordon 2011). This is because PTE has not only been shown to directly influence teachers' choice of use of innovative instructional techniques (Otanga \& Wang'eri, 2014) but also to generally influence human achievement in a variety of settings including education, health, sports and business (Beauchamp, Klassen, Parsons, Durksen \& Taylor, 2014). According to Zhao and Cziko (2001) as cited in Teo (2009), highly efficacious teachers are more likely to implement instructional innovation in the classroom. Similarly, Khurshid, Qasri and Ashraf (2012) maintain that teachers with high efficacy have confidence in adopting difficult and risky innovative strategies and are open to new ideas and skills. More importantly, studies have linked teachers' efficacy and students' learning outcomes (Joice \& Calhoun, 2010; Klassen, Tze, Betts \& Gordon 2011).

PTE is an individual teacher's belief of his/her ability to make a difference in learners' lives. It is the 'teacher's judgment of his or her capabilities to bring about desired outcomes of student engagement 
and learning (Tschannen-Moran \& Hoy, 2001, p. 783). It is one's self-judgment of personal capabilities to initiate and successfully perform specific tasks at designated levels, expend greater effort, and persevere in the face of adversity (Bandura, 1986). In this regard, PTE is perceived to influence teachers' instructional behavior, classroom organization and feedback patterns to students. According to Gist and Mitchell (1992) it is an individual's judgement about task capability that is not inherently evaluative. Similarly, Lewandowski (2005) is categorical that efficacy expectations relate to how confident an individual believes him/herself to be in carrying out an action in an effort to reach the goal. According to the researcher, the level of confidence determines how persistent one may or may not be in carrying out an action. Thus, individuals who have high expectancies for both types of expectations are ensured greater success as they will continue to be persistent when confronted by difficulties that hamper steady progress. Those who have low expectancies will falter in the presence of difficulty.

Studies including Bandura (1986, 1977) and Hoy (2000) have suggested four sources of teacher efficacy: mastery experiences, vicarious experiences, verbal persuasion, and physiological arousal. Such studies maintain that these factors predict teacher effectiveness as well as influence instructional strategies they choose to use in their teaching. Unfortunately, little data exist that could directly link PTE and choice of instructional variation (Looney, 2003, Otanga \& Wang'eri 2014). Additionally, existing studies present contradictory findings on the link between demographic factors and PTE. While some studies (Egger, 2006; Gur, Cakiroglu \& Aydin, 2012; Hoy \& Woolfolk, 1993) found out that gender, teaching experience and support from colleagues were not significant predictors of teacher efficacy, others, such as (Kurz, 2001) have found differences in PTE on the basis of gender. A further review of the literature shows that researchers omit demographic variables in their analyses of predictors of PTE. For instance, a study by Ross, Cousins and Gadalla (1996) collected demographic information of teacher's years of teaching experience, gender, level of education and subject area but failed to include such information in their analysis. It is therefore difficult to identify the role of such variables in PTE.

Research on determinants of PTE also indicates mixed findings. While some studies (Capa, 2005; Tschannen-Moran \& Hoy, 2001) report that support from colleagues within the department was not correlated with PTE, others (Looney, 2003) show that teacher efficacy was significantly and positively related to teachers' perceptions of a departmental community. PTE was also significantly and positively correlated with verbal persuasion and teachers' views of colleagues as proficient teaching models. Otanga and Wang'eri (2014) in a study of predictors of primary school teachers' efficacy concluded that teacher efficacy is influenced by general as well as specific teacher factors, and thus advised a multi-sectoral approach for the commissioning of Information Technology-based learning in schools. Finally, research in the area of PTE is limited in Africa in general and Kenya in particular. It is noted that available studies seem to focus on the relationship between PTE and classroom management styles (Sridhar \& Semana, 2011) as well as PTE in the use of ICT by teachers (Batchelor, 2011).

\subsection{Statement of the Problem}

In response to rising concern on declining standards in learner achievement and the need to keep pace with the rest of the world, the Government of Kenya in consultation with other stakeholders have endeavoured to among other things improve classroom pedagogy. Such efforts have seen the move to include the use of latest technology tools such as computer and other support materials collectively referred to as IT for use in the classroom. Nonetheless, acquisition of infrastructure has never automatically meant their use. Rather, users (teachers) perception of the existing conditions and remedies to the circumstances has been shown to be the direct answer. This is so because teachers are the primary agents in implementing the curriculum. It means their personal perceptions concerning the prevailing conditions as well as their ability to contribute in turning around the circumstances through use of such materials ultimately influence instructional strategies they adopt. In short, Personal Teacher Efficacy is an indicator of their willingness or otherwise to embrace a given circumstance. An understanding of teachers' PTE could thus best inform the process of rollout of such infrastructure for use in classroom pedagogy.

Though data on PTE seems to exist, much of this work has its origin outside Africa. None exist that provides an insight on secondary education management of classroom pedagogy in Kenya. Additionally, most of the existing data show minimal direct link between PTE and teachers' choice of 
teaching method. Further, their analysis indicates inconsistencies regarding the sources of efficacy information. The scarcity of data in the area of PTE in secondary education in Kenya demands that studies be undertaken. This study therefore sought to assess the influence of PTE on the choice of teaching methods among secondary school teachers in Kwale County as a contribution in furthering this line of research.

\subsection{Research Question}

The study therefore set to answer the following questions:

i. What is the level of personal teacher efficacy among secondary school teachers?

ii. What is the influence of demographic characteristics of age, gender, level of education and years of teaching experience to personal teacher efficacy?

iii. How does feedback of task performance influence personal teacher efficacy?

iv. What is the influence of academic department on personal teacher efficacy?

v. What is the influence of teacher's mastery of teaching methods on personal teacher efficacy?

vi. To what extent do demographic variables, vicarious experiences, verbal persuasion and mastery experiences determine choice of instructional methods?

\section{THEORETICAL FrameWORK}

The study is grounded on social cognitive theory, developed by Albert Bandura (1977, 1997). Social cognitive theory assumes that people are capable of human agency, or intentional pursuit of courses of action, and that such agency operates in a process called triadic reciprocal causation. Reciprocal causation is a multi-directional model suggesting that our agency results in future behavior as a function of three interrelated forces: environmental influences, our behavior, and internal personal factors such as cognitive, affective, and biological processes. Relative to this study, it is presumed that teacher efficacy is a product of teacher's interpretation of the four sources of information on efficacy i.e. verbal persuasion, vicarious experience, mastery experiences and physiological arousal though the information is interpreted differently by each individual. Consequently, judgments about efficacy are dependent on the interaction of demographic (age, gender, level of education, teaching experience and mastery of teaching methods) and contextual factors (support from colleagues in the academic department).

\section{RESEARCH MeTHODOLOGY}

\subsection{Participants and Procedure}

Participants were 121 (76 male, 45 female) practicing teachers. The respondents were told that the study aimed at improving their teaching in schools. Respondents completed a questionnaire comprising of items adapted from the Teachers' Sense of Self-Efficacy Scale (Tschannen-Moran \& Hoy, 2001) and the Mentor Support Scale (Capa \& Loadman, 2004). Teachers completed the questionnaire in the staffroom during free time.

\subsection{Measures}

Vicarious experiences. Seven items measured vicarious experiences which were sub-divided into three. Vicarious 1 was the extent to which the teacher observed other teachers during task performance; Vicarious 2 was the extent to which the teacher was observed during task performance and Vicarious 3 was the extent to which the teacher received feedback from the department. Mean scores were made for each of the three groups. Sample items included "My colleagues in the department allow me to observe their lessons and discuss their instructional objectives', 'How often in the past one year have you visited another teacher's classroom within your department to observe their teaching?' and 'How often in the past one year have you received feedback concerning teaching methods (formally or informally) from teachers within your department'? The ratings were made on a 5-point scale.

Verbal persuasion. Four items measured the extent to which teachers identified with the teaching strategies of other members of the department and modelled after them through reciprocal influence (e.g. 'I believe teachers in our department are capable of incorporating a variety of instructional 
methods' and 'I have learned better instructional techniques by observing teachers from our department in the classroom'. The ratings were made on a 5-point scale and a mean score was computed for the items.

Mastery of techniques. An item each measured the extent of mastery of lecture, group work and use of Information Technology.

Instructional techniques. Four items measured the extent of use of both traditional and innovative techniques. The former consisted of the use of lecture and group work methods while the latter comprised of the use of IT in teaching. Mean scores of the items were computed.

Personal Teacher Efficacy. Teachers rated their perceived ability to incorporate a variety of instructional practices in teaching and their general ability to teach. The scale consisted of 2 items (e.g. 'I feel I have the ability to incorporate a variety of innovative instructional practices in my lessons' and 'I am confident in my ability to teach') and all ratings were made on a 5-point scale ( $1=$ strongly disagree, $5=$ strongly agree). A mean score of the 2 items was computed.

\section{FINDINGS}

\subsection{Level of Personal Teacher Efficacy}

First and foremost, the study intended to determine PTE for Kwale County secondary school teachers. To achieve this, teachers' score for the perception of their ability to incorporate innovative instructional practices, their ability to use appropriate teaching techniques and overall PTE were assessed. Findings showed that teachers rated both their ability to incorporate a variety of innovative instructional practices in their lessons and their ability to use appropriate teaching techniques that incorporate the use of IT to help learners discover ideas and master concepts highly, $(\mathrm{M}=4.17, \mathrm{SD}=.81$ and $\mathrm{M}=4.03, \mathrm{SD}=.81$ respectively). In general, PTE was also high $(\mathrm{M}=12.74, \mathrm{SD}=1.91)$. This observation conforms to other previous research findings. For instance, Adedoyin (2010) in a study of junior secondary school teachers' self-efficacy found that it was based on their professional abilities in the classroom to create a conducive learning and teaching atmosphere for effective learning outcomes. However, it is contrary to Rangraje (2002) whose study categorically concluded that many teachers have a low sense of efficacy making it difficult for them to cope with the challenges of their educational environment.

\subsection{Demographic Characteristics and Personal Teacher Efficacy}

Secondly, the study set out to assess the existing relationship between demographic characteristics of age, gender, teaching experience, department and workload. Data obtained from an analysis of the existing relationship was as summarized in Table 1 in the appendix. Results showed that $30 \%$ of the total variance in PTE was accounted for by the teachers' demographic characteristics. This means that teachers' demographic characteristics explained about a third of the total variance in their PTE. Specifically, findings show that teachers aged 25-45 reported highest personal teacher efficacy $(\mathrm{M}=13.33, \mathrm{SE}=.20)$ and male teachers reported higher teacher efficacy $(\mathrm{M}=13.18, \mathrm{SE}=.10)$. Further, teachers who had taught between 11-15 years reported similar high levels of PTE $(\mathrm{M}=14.00$, $\mathrm{SE}=.30)$. At the same time, teachers in the science department recorded highly for PTE $(\mathrm{M}=13.33$, $\mathrm{SE}=.21)$ while those in the language department reported the lowest PTE $(\mathrm{M}=11.94, \mathrm{SE}=.15)$. Finally and interestingly, teachers with the highest workload also recorded the highest teacher efficacy $(\mathrm{M}=14.00, \mathrm{SE}=.32)$. Age was also found to be strongly and significantly correlated to teaching experience $(\mathrm{R}=.857, \mathrm{p}=<.001)$, negatively and significantly correlated to use of traditional methods of teaching $(\mathrm{R}=-.368, \mathrm{p}<.001)$, use of innovative methods of instruction $(\mathrm{R}=-.241, \mathrm{p}=.008)$ and generally PTE $(\mathrm{R}=-.238, \mathrm{p}=.009)$. The model which was significant illustrated that age, gender and teaching experience each had a negative significant influence on teacher efficacy, $(\beta=-.514, p=.009 ; \beta=-.966$, $\mathrm{p}=.005$ and $\beta=-.948, \mathrm{p}<.001$ respectively).

The finding concerning the relationship between teachers' age and gender and their PTE partly agrees with that of Otanga and Wang'eri (2014) who though acknowledged that teachers in the $35-45$ age brackets had the highest PTE noted higher PTE for female than male teachers. Age had a strong negative correlation with PTE, which is consistent with findings by Hartfield (2011) who showed teacher's experience to be associated with teacher efficacy. It also offer partial support to Kurz (2001) cited in Capa (2005) who found gender differences on teacher efficacy ratings. However, and in line with previous research, the findings on age and gender as demographic factors contradicts a number 
of studies (Egger, 2006; Gur et al., 2012; Hoy \& Woolfolk, 1993; Khurshid et al., 2012) who found no relationship between teachers' demographic characteristics and teacher efficacy.

With regard to teaching experience and teacher efficacy, findings partially supports those of Soodak and Poodell (1997) who found though teacher efficacy was initially high for the elementary teachers during the pre-service teaching years, in the first year of teaching it fell dramatically and with more years of teaching experience, it gradually increased though their own sense of effectiveness never reached the same levels achieved by secondary-level teachers. This illustration seems to explain the subsequent dip in teacher efficacy for teachers with more than 15 years of teaching experience. The implication is that the low levels of efficacy found among novice teachers (1-5 years) indicates that teacher efficacy is not directly related to age and years of teaching experience alone among this sample but probably with other factors. It also corroborates findings by Hartfield (2011) who found somewhat lower mean self-efficacy beliefs among novices than among career teachers. This lower assessment of their teaching capabilities is linked to the relative inexperience of these teachers. This means that a complete understanding of teacher efficacy requires taking into account two different kinds of factors: general demographic factors common to all teachers as well as more personal factors specific to each teacher.

Relative to departments, PTE was found to be high for Science than Language, Mathematics and humanities teachers which seem to lend support to Gerges (2001) as well as Otanga and Wang'eri (2014). While the later categorically stated that Science teacher have higher PTE, the former in a qualitative study found that a teacher's subject area influenced their choice of teaching methods. Three participants in the study expressed the belief that while some content areas, such as science and social studies, lend themselves to student-centered methods, others such as mathematics and reading did not. A substantial number of studies support the notion that teachers do possess beliefs about content, and that such beliefs tend to shape the nature of their instructional practices (Blanton \& Moorman, 1987; Brophy \& Good, 1974; Nespor, 1987, cited in Gerges, 2001).

\subsection{Vicarious Experience and Personal Teacher Efficacy}

Additionally, an inquiry was made on the influence of vicarious experience on PTE. To achieve this, a hierarchical regression analysis of the existing relationship between $V_{1}$ (teacher observing others in task performance), $\mathrm{V}_{2}$ (other teachers observing the teacher in task performance), $\mathrm{V}_{3}$ (receiving feedback on task performance) and PTE was operationalized. The model used which was found to be insignificant showed that cumulatively, vicarious experiences accounted for $2.5 \%$ of the total variance in teacher efficacy. When entered into the model, vicarious 1 accounted for $0.4 \%$ of the total variance, $F(1,119)=.484, \mathrm{p}=.488$. Vicarious 2 and vicarious 3 explained $1.1 \%$ and $1.0 \%$ variance in teacher efficacy respectively $F(2,118)=1.365, \mathrm{p}=.245$; $F(3,117)=1.194, \mathrm{p}=.277$. Vicarious 1 was found to have an insignificant positive influence on PTE $(\beta=.083, p=.488)$, Vicarious 2 and Vicarious 3 each had an insignificant negative influence on PTE, $(\beta=-.305, p=.245$ and $\beta=-.085, p=.277$ respectively). The findings seems to be in tandem with that of Otanga and Wang'eri (2014) who observed that vicarious experience do not significantly influence the development of teacher efficacy and explained that isolation and maintaining a low sense of inter-dependence does not cultivate an environment for teachers to learn from models. However, it contradict Rangraje (2002) who found a large number of respondents $(68 \%)$ to have indicated significant disharmony amongst teachers.

\subsection{Verbal Persuasion and Personal Teacher Efficacy}

Likewise, an inquiry was made on the influence of verbal persuasion on PTE. On its own, verbal persuasion had a positive though insignificant correlation with teacher efficacy $(\mathrm{R}=.154, \mathrm{p}=.091)$. The regression equation was also found to be insignificant $F(1)=2.91,, \mathrm{p}=.091$. After controlling for the effects of demographic variables and vicarious experiences, verbal persuasion contributed an additional $1.1 \%$ to the variance in teacher efficacy. The hierarchical regression model was also found to be insignificant $F(7,113)=1.863, \mathrm{p}=.175$. The findings contradict that of previous researchers including LoCosale-Crouch (2013) and Looney (2003) who found that teacher efficacy is related to verbal persuasion and vicarious experiences through mentorship. Results from hierarchical regression analyses in Looney's study indicated that perception of a departmental professional community was a significant and positive predictor of teachers' overall efficacy and efficacy for classroom management, instructional practices, and student engagement. Additionally, teachers' perception of shared norms and values within the department was the strongest and most consistent predictor of efficacy. 


\subsection{Mastery of Teaching Techniques and Personal Teacher Efficacy}

The study also sought to establish the contribution of mastery experiences on teacher efficacy. Mastery of subject content was expected to provide the most direct feedback of teachers' capabilities thus its contribution to PTE. Respondents scored highly for ability to incorporate a variety of innovative instructional techniques in their lessons $(\mathrm{M}=4.17, \mathrm{SD}=.81)$, their ability to teach $(\mathrm{M}=4.54$, $\mathrm{SD}=.74$ ) and their ability to use appropriate teaching techniques that incorporate the use of IT to help learners discover ideas and master skills $(\mathrm{M}=4.03, \mathrm{SD}=.81)$. Mastery was significantly and negatively correlated to teachers' age, gender and teaching experience, $(\mathrm{R}=-.238, \mathrm{p}=.009 ; \mathrm{R}=-.256, \mathrm{p}=.005$ and $\mathrm{R}=-.408, \mathrm{p}<.001$ respectively $)$. It was also strongly but positively correlated to PTE $(\mathrm{R}=1.00, \mathrm{p}<.001)$ indicating a strong and positive significant relationship. It contributed $68.9 \%$ of variance in teacher efficacy implying that mastery is a significant predictor $F(8,112)=15.88, \mathrm{p}<.001$. This finding is in agreement with among others Teo (2009) and Yan (2002). While the former noted a weak positive correlation between mastery and PTE, Yan (2002) found that mastery in Information Technology was a significant predictor of the intention to use innovative teaching techniques including use of Information Technology and student-centred techniques. Collectively these studies provide strong support to Bandura (1997) who regarded mastery experiences as the most powerful influence on teachers' self-efficacy beliefs. The direction of effects of mastery on PTE in the present study suggests that teachers are highly likely to choose innovative instructional techniques if they are skilled in Information Technology which conforms with that of Otanga and Wang'eri (2014) who also suggested that by allowing teachers to gain mastery in teaching using IT, their likelihood of use of innovative techniques increases.

\subsection{Determinants of Teachers Choice of Teaching Techniques}

Lastly, an inquiry was made on predictors of teachers' use of traditional and innovative instructional techniques. Two hierarchical regression models were used for this, one for each instructional technique. In each of the model, age as a demographic characteristic was identified as a significant predictor, $F(1,119)=-4.32, \mathrm{p}<.001 ; F(1,119)=-2.71, \mathrm{p}=.008$ for traditional and innovative techniques respectively), teachers in the $25-45$ age bracket being more keen adopters of each of the two instructional strategies than those aged above 45 or below 25 years. Teaching experience was a significant predictor of use of innovative technique $F(3,117)=-3.88, \mathrm{p}<.001$; teachers with $11-15$ years of teaching being more active users of the instructional technique. This finding contradicts Otanga and Wang'eri (2014) who found no link between demographic variables and teachers' choice of instructional techniques and Yan (2002) who found no link between gender and choice of instructional methods.

Vicarious experiences and verbal persuasion were each found to be insignificant predictors while mastery was a significant positive predictor of the use of traditional technique of instruction $F(6,114)$ $=.320, \mathrm{p}=.750 ; F(7,113)=-.752, \mathrm{p}=.453$ and $F(8,112)=3.13, \mathrm{p}=.002$ respectively. The regression equations were significant. The overall model accounted for $27.4 \%$ of variance in use of traditional techniques and was also significant $\mathrm{F}(8,112)=9.80, \mathrm{p}=.002$. This finding partly contradicts Gerges (2001) who found no relationship between instructional variation and teachers' efficacy. It also partly corroborates assertions of Otanga and Wang'eri (2014) who established vicarious experiences, verbal persuasion and mastery as predictors of primary school teachers' choice of instructional techniques.

With regard to innovative instructional technique, the overall regression model accounted for $30.1 \%$ of variance in the use of innovative techniques and $32.9 \%$ of its prevalence $($ Beta $=.329)$. The model was significant $F(8,112)=20.62, \mathrm{p}<.001$. Separately, vicarious experiences and verbal persuasion were not significant predictors of teachers' use of innovative techniques. However, mastery and teacher efficacy were found to be very significant predictors of the use of innovative techniques accounting for $23.4 \%$ of variance, $F(1,119)=36.40, \mathrm{p}<.001, \mathrm{~B}=.368, \mathrm{SE}=.061, \mathrm{t}=6.03$. This finding corroborates Yan (2002) who found out that teachers used more Information Technology when they have high mastery level of information technology $(\mathrm{r}=.436, \mathrm{p}<.05)$.

\section{Conclusions OF THE Study}

The study set out to determine sources of personal teacher efficacy and their influence on teachers' choice of instructional techniques. Findings isolated teacher's demographic characteristics of age, gender and teaching experience as well as their mastery of teaching techniques as the main sources of teachers PTE. Similarly, the study illustrated that teacher's age, teaching experience and mastery were 
significant predictors of their choice of instructional techniques. The findings imply regular inservicing of practicing teachers is necessary to enable their adoption of innovative teaching strategies. Particular attention could be given to female teachers as well as teachers in the language and humanities department who registered low PTE with regard to adoption of innovative teaching strategies. Additionally, it is important that departments be strengthened by recruiting more teachers to enable mentorship.

\section{REFERENCE}

Adedoyin, O.O. (2010). Factor-analytic study of teachers' perceptions on self-efficacy in Botswana Junior Secondary Schools: Implications for educational quality. European Journal of Educational Studies, 2, 139-155.

Bandura, A. (1986) Social foundations of thought and action: A social cognitive theory. Englewood Cliffs, NJ: Prentice Hall.

Bandura, A. (1997). Self-Efficacy: The Exercise of Control. New York: W. H. Freeman \& Company.

Batchelor, J. (2011). Innovative teachers' pedagogical efficacy in their use of emerging technologies. Unpublished doctoral thesis. University of Pretoria. South Africa.

Beauchamp, L., Klassen, R., Parsons. J. Durksen, T. \& Taylor, L. (2014). Exploring the Development of Teacher Efficacy through Professional Learning Experiences. The Alberta Teachers' Association.

Capa, Y., \& Loadman, W.E. (2004). Evaluation of mentoring practices experienced by student teachers during teacher preparation program. Paper presented at the annual meeting of the American Educational Research Association, San Diego.

Capa, Y. (2005). Factors influencing first year teachers' sense of efficacy. Unpublished doctoral dissertation. The Ohio State University.

Egger, K.J. (2006). An exploration of the relationships among teacher efficacy, collective teacher efficacy and teacher demographic characteristics in conservative Christian schools. Unpublished doctoral dissertation. University of North Texas.

Gerges, G. (2001). Factors influencing preservice teachers' variation in use of instructional methods: Why is teacher efficacy not a significant contributor? Teacher Education Quarterly, 71-88.

Gur, G., Cakiroglu, J. \& Aydin, Y.C. (2012). Investigating predictors of sense of efficacy beliefs of classroom, science and mathematics teachers. Education and Science, 37, 68-76.

Hartfield, K.N. (2011). Perceived levels of personal teacher efficacy among secondary Arizona Agricultural Education teachers. Unpublished master's thesis. University of Arizona.

Hoy, A.W. (2000). Changes in teacher efficacy during the early years of teaching. Paper presented at the annual meeting of the American Educational Research Association, New Orleans, LA.

Hoy, W. K. \& Woolfolk, A. E. (1993). Teachers' sense of efficacy and the organizational health of schools. The Elementary School Journal, 93, 356-372.

Khurshid, F., Qasmi, F.N. \& Ashraf, N. (2012). The relationship between teachers' self-efficacy and their perceived job performance. Interdisciplinary Journal of Contemporary Research in Business, 3, 204-223. Retrieved from ijcrb.webs.com

Lewandowski, K.L. (2005). A study of the relationship of teachers' self-efficacy and the impact of leadership and professional development. Unpublished doctor of education thesis. Indiana University of Pennsylvania.

LoCosale-Crouch, J., Davis, E., Wiens, P \& Pianta, R. (2013). The role of the mentor in supporting new teachers: Associations with self-efficacy, reflection and quality. Mentoring and Tutoring: Partnership in Learning, 20(3), 3030-323.

Looney, L. (2003). Understanding teachers' self-efficacy beliefs: The role of professional community. Unpublished doctoral dissertation, University of Maryland, College Park.

Miima, F. Ondigi, S.R. \& Mavisi, R. (2013). Teachers' perception about integration of ICT in teaching and learning of Kiswahili language in secondary schools in Kenya. International Journal of Arts and Commerce, 2(3) (March 2013). 
Ogembo, J. O., Ayot, H. O. \& Twoli, N. W. (2015). Background characteristics, attitude, computer anxiety and self - concept as predictors of science and mathematics teachers'extent of integration of computer in classroom teaching in public secondary schools in Kwale County, Kenya.

Proceeding of the $4^{\text {th }}$ ICE, July 14 -16, 2015. pg 21 -29. http://cuseinKenya.syr.ed/

Otanga, H. \& Wang'eri, T. (2014). Sources of personal teacher efficacy and influence on teaching methods among teachers in primary schools in coast province, Kenya. Global Journal of Interdisciplinary Social Sciences, Vol.3(3):190-195, www.gifre.org

Rangraje, I. (2002). The efficacy of teachers in a number of selected schools in KwaZulu-Natal. Unpublished doctoral dissertation. University of Zululand, South Africa.

Ross, J.A., Cousins, J.B. \& Gadalla, T. (1996). Within-teacher predictors of teacher efficacy. Teaching and Teacher Education, 12(4), 385-400.

Soodak, L., \& Podell, D. (1996). Teaching efficacy: Toward the understanding of a multi-faceted construct. Teaching and Teacher Education, 12, 401-412.

Sridhar, Y.N. \& Semana, J. (2011). Teacher efficacy and its relationship to classroom management style among secondary school teachers of Kigali city, Rwanda. Journal of Education and Practice, 2.

Teo, T. (2009). Examining the relationship between student teachers' self-efficacy beliefs and their intended uses of technology for teaching: A Structural Equation Modelling approach. The Turkish Online Journal of Educational Technology, 8(4), 7-16.

Tschannen-Moran, M. \& Hoy, A.W. (2001). Teacher efficacy: Capturing an elusive construct. Teaching and Teacher Education, 17, 783-805.

Yan, H. (2002). The effects of teacher efficacy on teaching method. The University of Hong Kong.

\section{Appendix}

Table1. Influence of Demographic Variables on Teachers' PTE

\begin{tabular}{|c|c|c|c|c|c|}
\hline Variable & Mean & SE & $\beta$ & $\mathrm{R}^{2}$ & Sig \\
\hline \multicolumn{6}{|l|}{ Age (yrs) } \\
\hline Below 25 & 12.71 & .13 & -.514 & .056 & .009 \\
\hline $25-34$ & 13.33 & .27 & & & \\
\hline $35-45$ & 13.33 & .13 & & & \\
\hline Above 45 & 12.13 & .17 & & & \\
\hline \multicolumn{6}{|l|}{ Gender } \\
\hline Male & 13.18 & .10 & -.966 & .060 & .005 \\
\hline Female & 12.20 & .13 & & & \\
\hline \multicolumn{6}{|c|}{ Teaching Experience (yrs) } \\
\hline Below 5 & 10.25 & .23 & -.948 & 159 & .000 \\
\hline $5-10$ & 13.79 & .22 & & & \\
\hline $11-15$ & 14.00 & .30 & & & \\
\hline $16-20$ & 13.35 & .11 & & & \\
\hline Above 20 & 12.17 & .19 & & & \\
\hline \multicolumn{6}{|l|}{ Departments } \\
\hline Humanities & 13.12 & .14 & .151 & .010 & 205 \\
\hline Languages & 11.94 & .15 & & & \\
\hline Mathematics & 13.20 & .20 & & & \\
\hline Science & 13.33 & .21 & & & \\
\hline Technical & 13.20 & .20 & & & \\
\hline \multicolumn{6}{|c|}{ Workload (No of lessons per week) } \\
\hline Below 25 & 12.81 & .13 & .320 & .007 & 292 \\
\hline $25-28$ & 12.79 & .10 & & & \\
\hline Above 28 & 14.00 & .32 & & & \\
\hline
\end{tabular}




\section{AUTHORS' BIOGRAPHY}

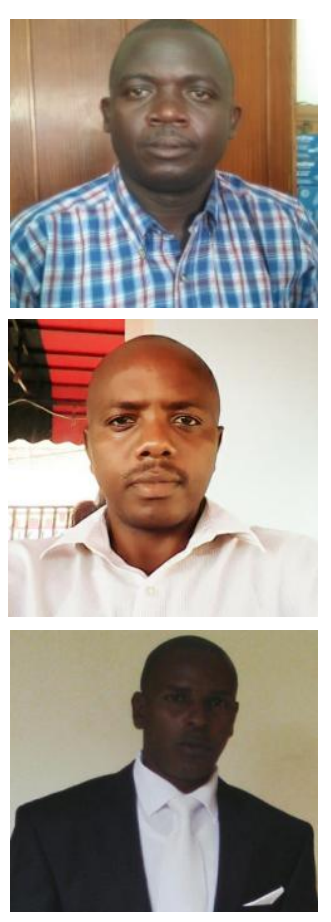

Mr. John Otieno Ogembo is an educationist with over 15 years teaching experience both at secondary and tertiary levels. An author of several articles on educational as well as socioeconomic related topics, Mr. Ogembo is currently a lecturer at the South Eastern Kenya University (SEKU) and a PhD candidate at Kenyatta University.

Dr. Leonard Mwathi Kamau is a lecturer of Mathematics and Mathematics Education at South Eastern Kenya University. A PhD graduate of Syracuse University in the US, Dr. Kamau is also the Chair of the Department of Educational Communication and technology and Ag. Chair of Education Foundation in the same University.

Mr Sammy Charagu Nduati teaches Chemistry and Mathematics at Kaharo girls high school in Murang'a County. He holds a MED (Education Technology) and BED (Sc) from Kenyatta University. Currently, he is a $\mathrm{PhD}$ (Education Technology) student at the same University.

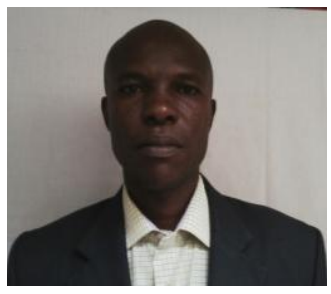

Mr Wilfred Mogire Monyoro is a Mathematics and Physics teacher with over ten years teaching experience. Currently teaching at Boitangare friends school in Kisii County, Mr Monyoro is also a PhD (Mathematics Education) student at Kenyatta University School of Education. 